\title{
Effect of Adding Different Concentrations of Alcohol Extracted Ginger as Feed Supplementation on Some Productive Traits of Broiler Chicken Ross Strain
}

\author{
Mohammed Jard Kadhim ${ }^{\mathrm{a}}$ \\ Muhammed Rasheed Rmul ${ }^{\mathrm{b}}$ \\ ${ }^{a, b}$ Department of Animal product, College of Technical Almusiab, University of Al-Furat Al-Awsat \\ Technical \\ mmmedm@yahoo.com_muhamedrrmul83@gmail.com
}

Submission date:- 1/9/2018 Acceptance date:- 26/9/2018 Publication date:- 27/1/2019

Keywords: broiler, alcohol extracted ginger, productive traits.

\begin{abstract}
This study was conducted in the poultry field that belong to Animal Production Techniques Department / Al musiab Technical College. To investigate the effect of alcohol extracted ginger supplementation in diet on some productive traits of broiler chicken ross strain. Two hundred fifty unsexed broiler chicks were equally divided into the five groups, 50 chicks per group, 2 replicates per group ( 25 chicks per replicate). Chicks were fed on starter diet (1 day- 3 week) and final diet (4-6 week), diets supplemented with five ratio from alcohol extracted ginger $(0$, $150,200,250,300 \mathrm{mg} / \mathrm{kg}$ ), the first group was control but the other represented experimental groups.

Results showed a significantly improve $(\mathrm{P} \leq 0.05)$ of average live body weight, weight gain, feed conversion ratio and dressing percentage in birds supplemented with alcohol extracted ginger as compared with control group at three and six week of birds age. As supplementation of alcohol extracted ginger had significantly $(\mathrm{P} \leq 0.05)$ decreased feed consumption and mortality ratio in experimental groups as compared with control group.
\end{abstract}

It can be concluded that supplementation of alcohol extracted ginger to diet had a positive effect to enhance productive traits of broiler chicken ross strain.

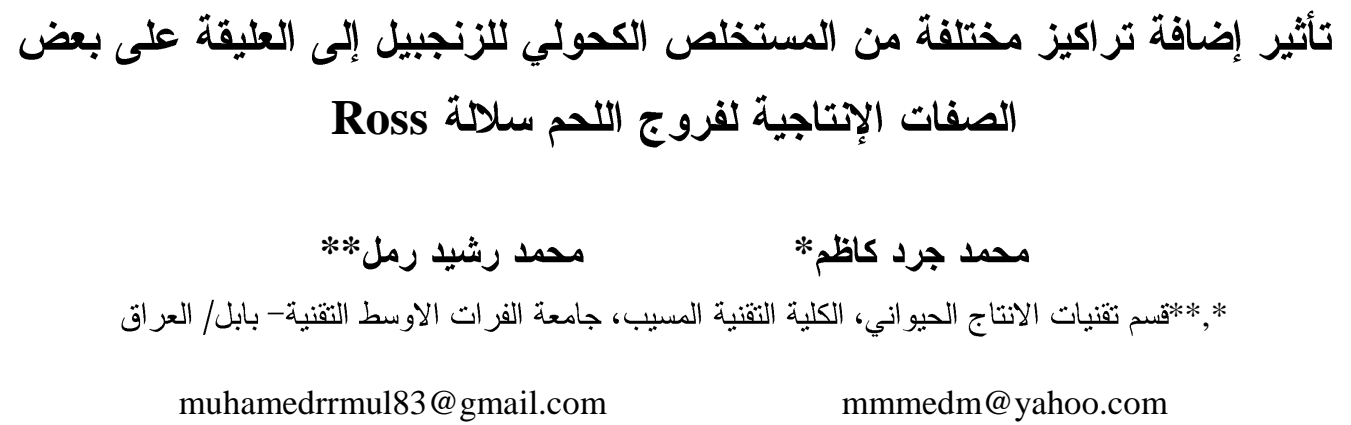




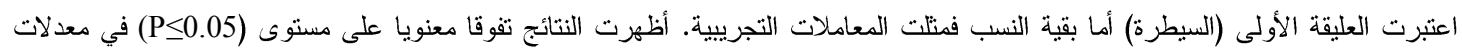

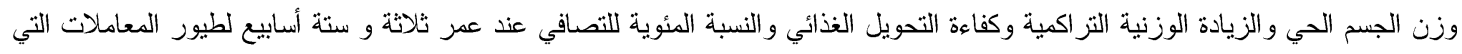
أضيف المستخلص الكحولي للزنجبيل في علائقها مقارنة مع معاملة السيطرة. كما أن نسبة استهلاك العلف و النسبة المئوية للهاكلاكات انخفضت

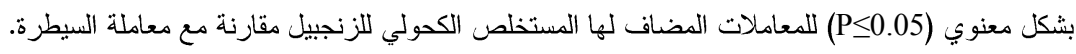

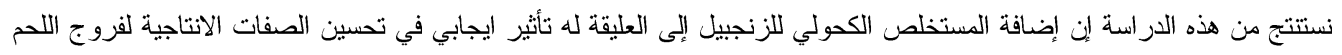

سلالة Ross.

الكلمات الالة: فروج اللحم, المستخلص الكحولي للزنجبيل, الصفات الانتاجية

- المقدمة

شهدت صناعة منتجات الدواجن في السنوات الأخيرة حصول نمو كبير وتطور سريع على نطاق و اسع مقارنة مع تصنيع منتجات اللحوم

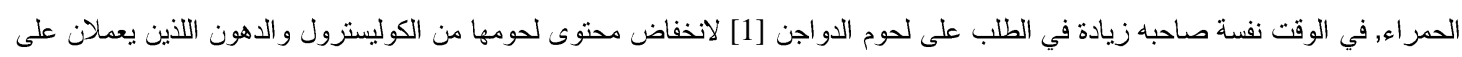

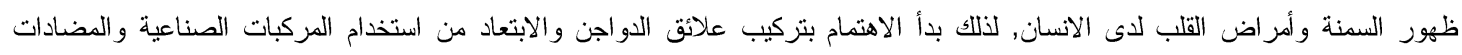

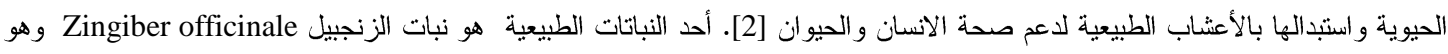

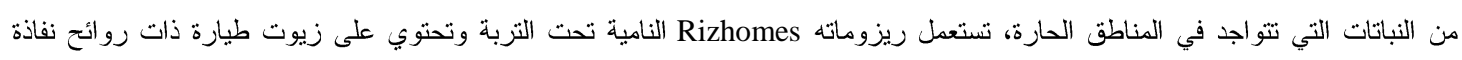

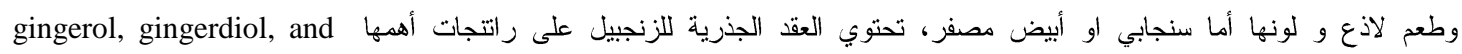
gingerdionel

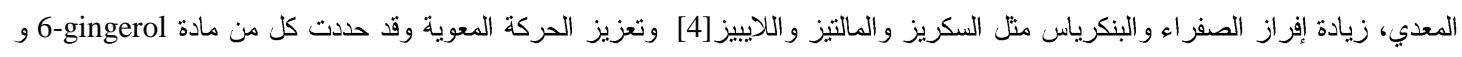

10-gingerol

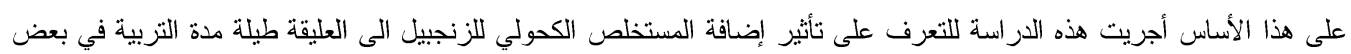

الصفات الإتتاجية لفروج اللحم سلالة هoss.

r- r r r المواد وطر ائق العمل

استخدم في هذه التجربة 250 فرخ فروج لحم غير مجنس عمر يوم واحد من سلالة روز وبمتوسط وزن 44 ـ 0 غن غم في حقل الطيور

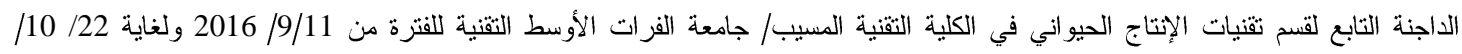
2016, وزعت الأفر اخ عشو ائيا على خمس معاملات تجريبية وشملت كل معاملة مكررين متساويين وبو اقع 25 طير لكل مكرر.

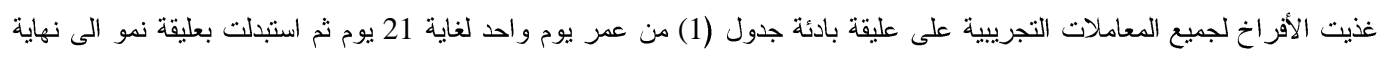
مدة التجربة 42 يوم, أضيف المستخلص الكحولي للزنجبيل إلى العليقة بالنسب 0, 150, 200, 250, 300 ملغم/ كغم علف لتصبح المعاملات التجريبية الاولى T1 (السيطرة) و T5 T2,T3,T2 للنسب المذكورة على التو الي.

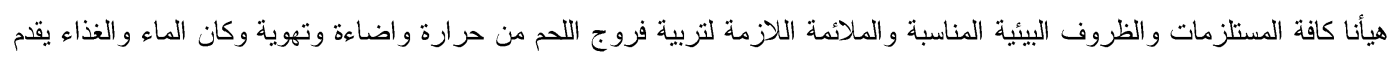
الى الافر اخ بصورة حرة adlibitum طيلة مدة النزبية. حصلنا على نبات الزنجبيل من الأسو اق المحلية وقطع الزنجبيل الخام اللى قطع صغيرة جدا كُلاً على حدة, بإذابة 30غم من المادة الخام ثم

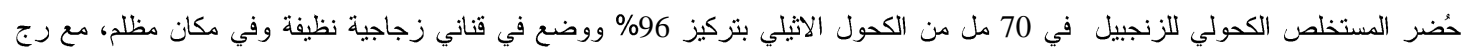

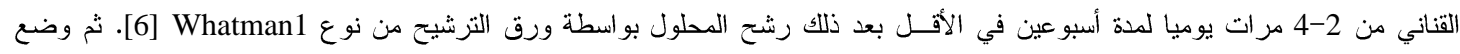

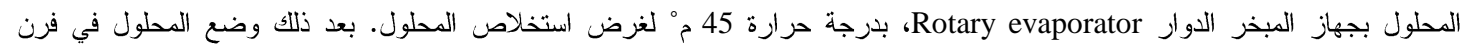

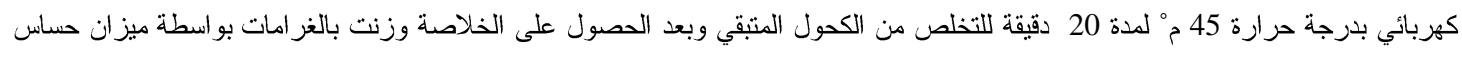

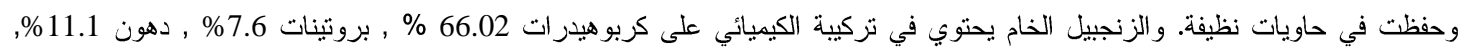

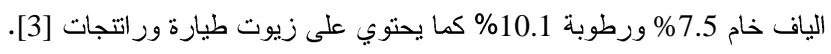

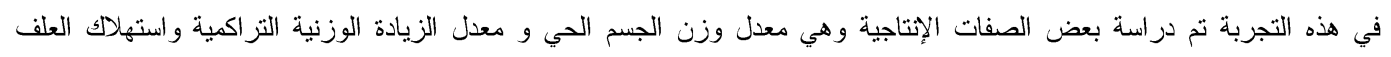

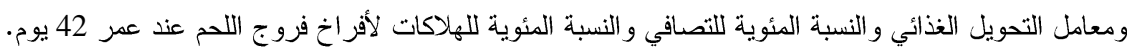

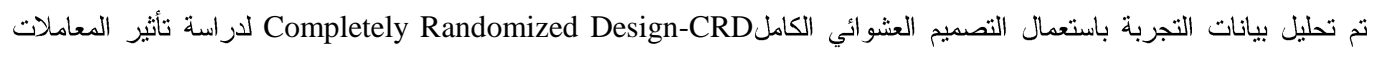
المختلفة في الصفات المدروسة, وقورنت الفروق المعنوية بين المتوسطات باختبار دنكن متعدد الحدود [7] واستخدم برنامج [8] في التحليل

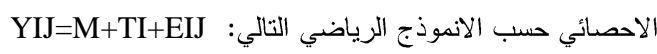

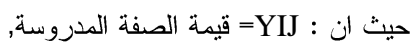

$$
\begin{aligned}
& \text { M المتوسط العام للصفة المدروسة, }
\end{aligned}
$$

EIJ 
جدول (1) نسب المواد العلفية الاخلة في التجربة (البادئة والنهائية) و التحليل الكيمياوي لها

\begin{tabular}{|c|c|c|}
\hline عليقة نهائية 22 - 42 يوم & عليقة بادئ 1 - 21 يوم & المادة العلفية \\
\hline 21 & 20 & حنطة \\
\hline 41 & 40 & ذرة صفراء \\
\hline 25 & 27 & كسبة فول الصويا \\
\hline 10 & 10 & "مركز بروتيني لحم"** \\
\hline 2.0 & 2.0 & زيت نباتي \\
\hline 0.4 & 0.4 & حجر كلس \\
\hline 0.4 & 0.4 & ملح طعام \\
\hline 0.1 & 0.1 & مثيونين \\
\hline 0.1 & 0.1 & لايسين \\
\hline \multirow[t]{2}{*}{100} & 100 & المجموع \\
\hline & & *ت"التحليل الكيمياوي المحسوب \\
\hline 20.96 & 22.08 & البروتين الخام \% \\
\hline 3102.3 & 2958.11 & الطاقة الممثلة (كيلو سعرة / كيلو غرام) \\
\hline 148.01 & 133.97 & نسبة الطاقة الممثلة / البروتين الخام \% \\
\hline 1.17 & 1.24 & \% اللايسين \\
\hline 0.80 & 0.85 & المثيونين + السستين \% \\
\hline 1.03 & 1.04 & \% كالسيوم \% \\
\hline 0.46 & 0.47 & فسفور \% \\
\hline 4.97 & 5.20 & الياف خام \% \\
\hline 3.43 & 3.42 & الاهن \% \\
\hline
\end{tabular}

* استخدم مركز بوتيني لحم مستورد من انتاج شركة بروفيمي اردني المنشأ يحتوي على 2200 كيلو سعرة طاقة ممثلة, 40 \% \% بروتين,

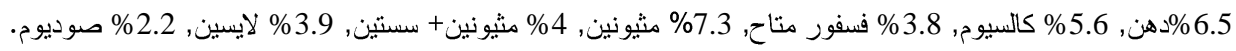

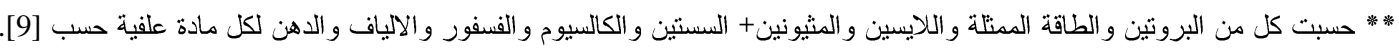

أظهرت النتائج في الجدول (r) تأثير ا واضحا لإضافة المستخلص الكحولي للزنجبيل في العلف على وزن الجسم الحي عند عمر ثلاثة أسابيع حيث لوحظ أن هنالك تفوقا معنويا (P

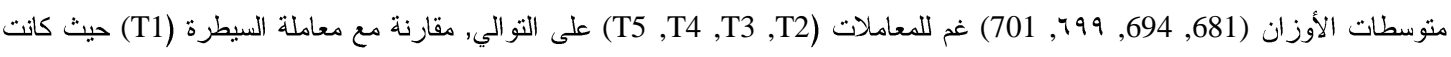

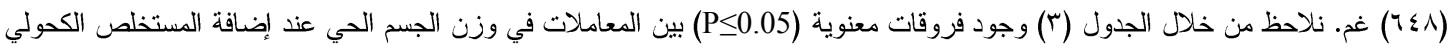
للزنجبيل للعليقة عند عمر ستة أسابيع, كما نلاحظ تفوق المعاملات المضاف لها المستخلص الكحولي للزنجبيل معنويا حيث كانت متوسطات

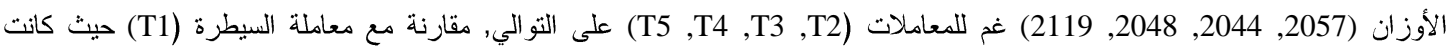
(1894) غم. ان سبب الزيادة الحاصلة في أوزان الجسم للطيور المغذات على العلف المعامل بالمستخلص الكحولي للزنجبيل ذات التراكيز 2000 التئ

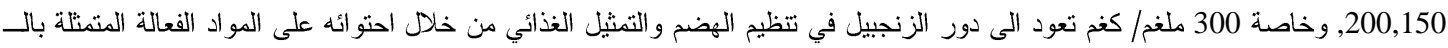
Zingiberen, gingerols and Shogaol

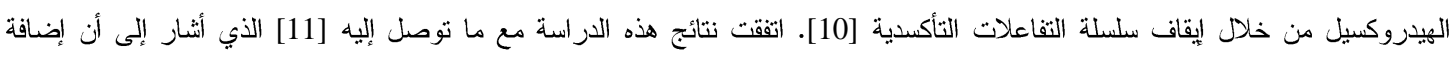
المستخلص الكحولي للزنجبيل ادى الى تحسن وزن الجسم الحي لطائر السمان.

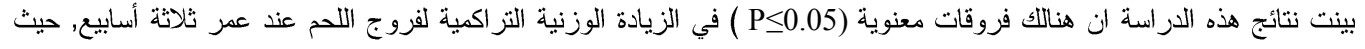

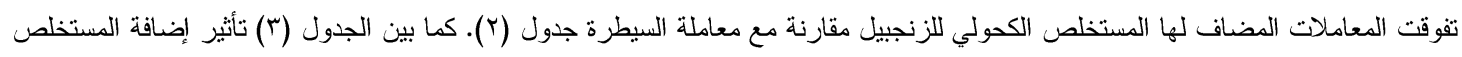

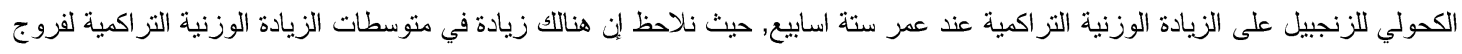

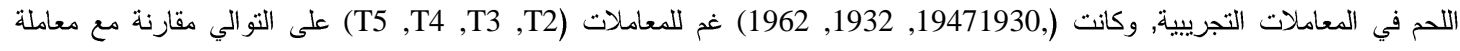

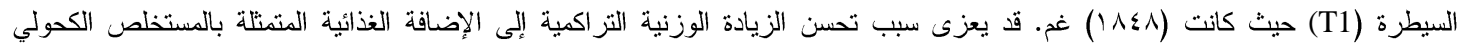


للزنجبيل, إذ قد يتسبب المستخلص في فتح الثهية عند الطيور التي غذيت على العلف المعامل بالمستخلص الكحولي للزنجبيل ومن ثم ازدياد وزنها، ذلك من خلال تحسين عملية الهضم لاى الطيور و الذي يعمل على تحفيز الإفراز المعدي و أيضا زيادة إفراز اللعاب و زيادة فعالية إنزيم

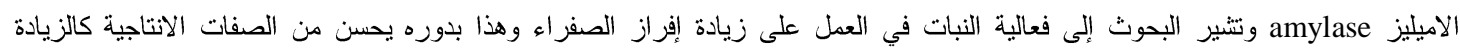

الوزنية [12].

جلول (2) تأثير إضافة المستخلص الكحولي للزنجبيل في العلف على وزن الجسم الحي والزيادة الوزنية التراكمية واستهلاك العلف الثراكمي ومعامل التحويل الغذائي لفروج النحم عند عمر ثنالثة اسابيع.

\begin{tabular}{|c|c|c|c|c|}
\hline \multicolumn{4}{|c|}{ المتوسط 土 الخطأ القياسي } & \multirow[b]{2}{*}{ المعاملات } \\
\hline معامل التحويل الغذائي (غم علف / غم زيادة وزنية) & نسبة العلف المستهلك التراكمي & الزيادة الوزنية التر اكمية & معدل وزن الجسم (غم) & \\
\hline $\begin{array}{c}1.70 \pm 0.023 \\
a\end{array}$ & $\begin{array}{c}1065 \pm 13.20 \\
a\end{array}$ & $\begin{array}{l}624 \pm 3.901 \\
\text { b }\end{array}$ & $\begin{array}{l}648 \pm 3.740 \\
a\end{array}$ & T1 \\
\hline $\begin{array}{l}1.61 \pm 0.025 \\
b\end{array}$ & $\begin{array}{l}1048 \pm 14.63 \\
\quad b\end{array}$ & $\begin{array}{l}648 \pm 3.283 \\
\mathrm{a}\end{array}$ & $\begin{array}{l}681 \pm 4.312 \\
\mathrm{a}\end{array}$ & $\mathbf{T} 2$ \\
\hline $\begin{array}{l}1.59 \pm 0.021 \\
b\end{array}$ & $\begin{array}{l}1033 \pm 13.36 \\
b\end{array}$ & $\begin{array}{l}647 \pm 4.227 \\
\mathrm{a}\end{array}$ & $\begin{array}{l}694 \pm 3.877 \\
\text { a }\end{array}$ & T3 \\
\hline $\begin{array}{l}1.59 \pm 0.021 \\
b\end{array}$ & $\begin{array}{l}1042 \pm 14.19 \\
b\end{array}$ & $\begin{array}{l}654 \pm 3.531 \\
\text { a }\end{array}$ & $\begin{array}{l}699 \pm 4.491 \\
\text { a }\end{array}$ & T4 \\
\hline $\begin{array}{l}1.60 \pm 0.024 \\
b\end{array}$ & $\begin{array}{l}1054 \pm 14.14 \\
b\end{array}$ & $\begin{array}{l}658 \pm 4.146 \\
a\end{array}$ & $\begin{array}{l}701 \pm 4.952 \\
\quad \mathrm{a}\end{array}$ & T5 \\
\hline$*$ & $*$ & $*$ & $*$ & مستوى المعنوية \\
\hline
\end{tabular}

المتوسطات التي تحمل حروف مختلفة ضمن العمود الواحد تختلف معنويا فيما بينها (P<0.05).

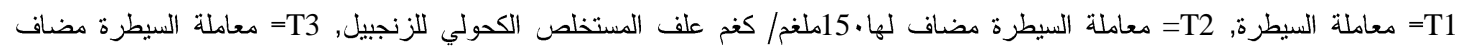

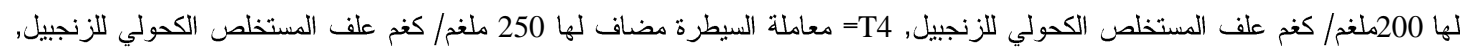
S5 =T5 =Tملة السيطرة مضاف لها 300 ملغم/ كغم علف المستخلص الكحولي للزنجبيل.

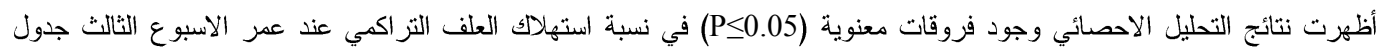
(r) و الاسبوع السادس جدول (r), حيث نلاحظ من خلال الجدولين ان اعلى نسبة استهلاك علف وجدت في معاملة السيطرة مقارنة مع المعاملات

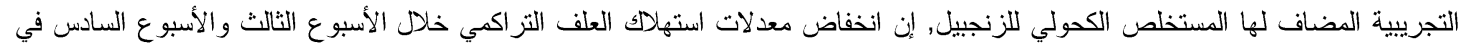

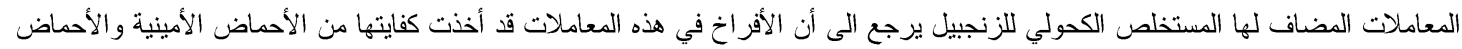

الدهنية والمعادن والفيتامينات, وقد يعود ذلك إلى تأثير المستخلص الكحولي للزنجبيل في تحفيز عمليات الايض والنيل النمو [5].

جدول (3) تأثير إضافة المستخلص الكحولي للزنجبيل في العلف على وزن الجسم الحي والزيادة الوزنية التراكمية واستهلاك العلف الثراكي ومعامل التحويل الغذائي لفروج اللحم عند عمر ستثة استابيع.

\begin{tabular}{|c|c|c|c|c|}
\hline \multicolumn{4}{|c|}{ المتوسط 土 الخطأ القياسي } & \multirow[b]{2}{*}{ المعاملات } \\
\hline فم زيادة التحويل الغذائي (غم علف / مزنية) & نسبة العلف المستهلك التر اكمي & 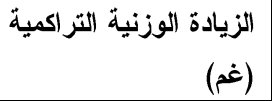 & معدل وزن الجسم (غم) & \\
\hline $\begin{array}{c}1.86 \pm 0.025 \\
\mathrm{a} \\
\end{array}$ & $\begin{array}{c}3447 \pm 4.85 \\
\mathrm{a} \\
\end{array}$ & $\begin{array}{c}1848 \pm 3.92 \\
\text { d } \\
\end{array}$ & $\begin{array}{c}1894 \pm 4.342 \\
\text { c } \\
\end{array}$ & T1 \\
\hline $\begin{array}{c}1.70 \pm 0.022 \\
b \\
\end{array}$ & $\begin{array}{c}3322 \pm 5.91 \\
\text { b }\end{array}$ & $\begin{array}{c}1947 \pm 4.78 \\
b\end{array}$ & $\begin{array}{c}2057 \pm 3.826 \\
\text { b } \\
\end{array}$ & $\mathbf{T 2}$ \\
\hline $\begin{array}{c}1.72 \pm 0.019 \\
b\end{array}$ & $\begin{array}{l}3321 \pm 4.35 \\
b\end{array}$ & $\begin{array}{c}1930 \pm 3.69 \\
c\end{array}$ & $\begin{array}{c}2044 \pm 4.756 \\
\text { b }\end{array}$ & T3 \\
\hline $\begin{array}{l}1.72 \pm 0.017 \\
b\end{array}$ & $\begin{array}{l}3318 \pm 4.55 \\
b\end{array}$ & $\begin{array}{c}1932 \pm 5.26 \\
c\end{array}$ & $\begin{array}{c}2048 \pm 3.583 \\
b\end{array}$ & T4 \\
\hline $\begin{array}{l}1.69 \pm 0.023 \\
b\end{array}$ & $\begin{array}{l}3320 \pm 5.20 \\
b\end{array}$ & $\begin{array}{c}1962 \pm 4.26 \\
a \\
\end{array}$ & $\begin{array}{c}2119 \pm 4.801 \\
a \\
\end{array}$ & T5 \\
\hline * & $*$ & * & * & مستوى المعنوية \\
\hline
\end{tabular}

المتوسطات التي تحمل حروف مختلفة ضمن العمود الواحد تختلف معنويا فيما بينها (P>0.05). 


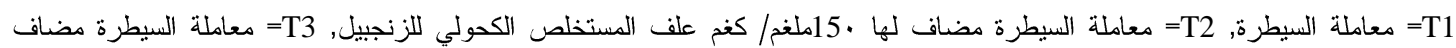

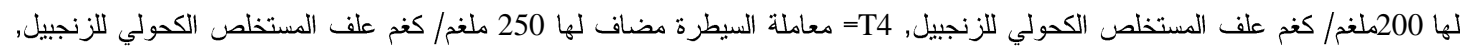
S55=T5 معاملة السيطرة مضاف لها 300 ملغم/ كغم علف المستخلص الكحولي للزنجبيل.

يوضح الجدول (r) والجدول (r) قيم معامل التحويل الغذائي لفروج اللحم عند عمر ثلاثة وستة أسابيع, أذ يلاحظ من خلال الجدولين

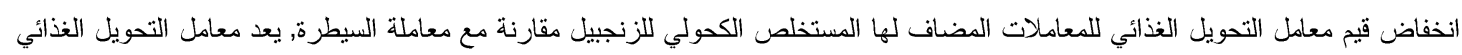

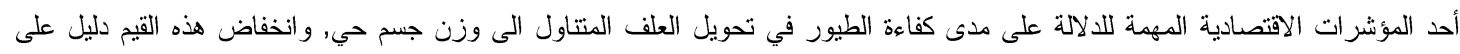
وجود تحسن في معامل التحويل الغذائي. تشيبر النتائج في هذه التجربة الى حدوث تحسن و اضح في المعاملات التي غذيت على عليقة مضاف لهاءئ المستخلص الكحولي للزنجبيل تركيز (150, 200, 250 و . .ب ملغم/ كغم) ربما يعود السبب في تحسن كفاءة التحويل الغذائي لهذه المعاملات

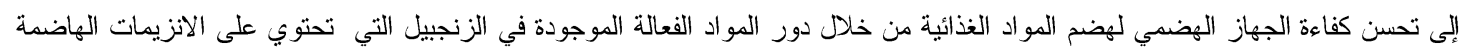

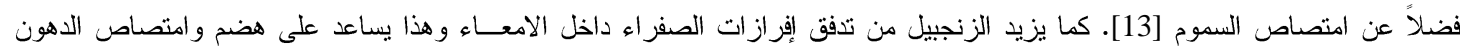

أثتبت نتائج الدراسة الحالية تأثير المستخلص الكحولي للزنجبيل في النسبة المئوية للهلاكات عند عمر ستة اسابيع لفروج اللحم, نلاحظ

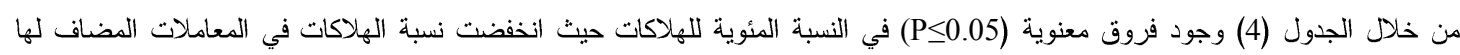

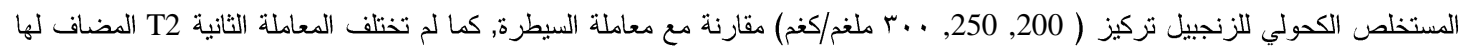

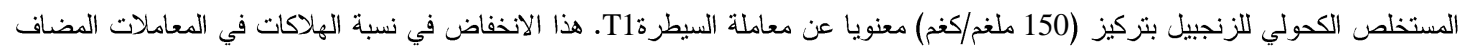

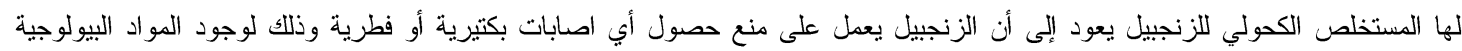

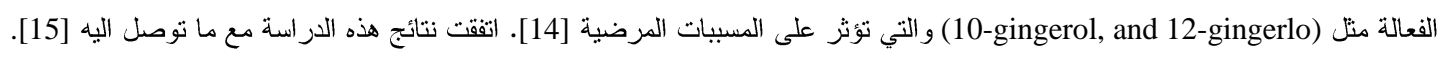
حيث اشار انه لا توجد هنالك أي هلاكات عند اضافة جذور نبات الزنجبيل الى عليقة فروج اللحم.

\section{جدول (4) تأثير إضافة المستخلص الكحولي للزنجبيل في العلف علي النسبة المئوية للهلاكات والنسبة المئوية للتصافي لفروج اللحم عند عمر}

\begin{tabular}{|c|c|c|}
\hline \multicolumn{2}{|c|}{ المتوسط 土 الخطأ القياسي } & \multirow[b]{2}{*}{ المعاملات } \\
\hline نسبة التصافي \% & نسبة الهلاكات \% & \\
\hline $\begin{array}{c}73.80 \pm 0.81 \\
b\end{array}$ & $\begin{array}{c}8.00 \pm 4.00 \\
b\end{array}$ & T1 \\
\hline $\begin{array}{c}76.62 \pm 0.51 \\
a\end{array}$ & $\begin{array}{c}6.00 \pm 2.00 \\
b\end{array}$ & T2 \\
\hline $\begin{array}{c}77.65 \pm 0.73 \\
a\end{array}$ & $\begin{array}{c}2.00 \pm 2.00 \\
a\end{array}$ & T3 \\
\hline $\begin{array}{c}76.81 \pm 0.64 \\
a\end{array}$ & $\begin{array}{c}0.00 \pm 0.00 \\
a\end{array}$ & T4 \\
\hline $\begin{array}{c}77.59 \pm 0.57 \\
a\end{array}$ & $\begin{array}{c}0.00 \pm 2.00 \\
a\end{array}$ & T5 \\
\hline * & * & مستوى المعنوية \\
\hline
\end{tabular}

المتوسطات التي تحمل حروف مختلفة ضمن العمود الواحد تختلف معنويا فيما بينها (P<0.05).

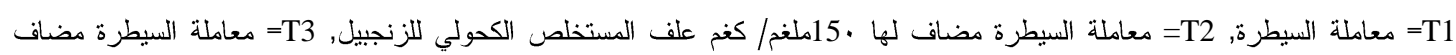

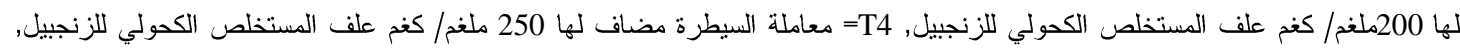
S5 =T5

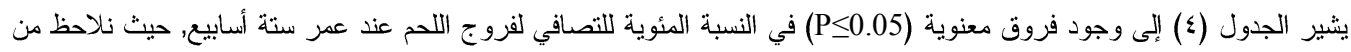

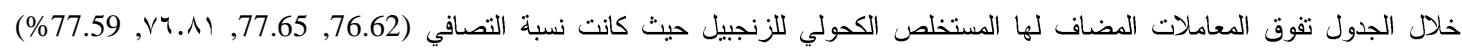

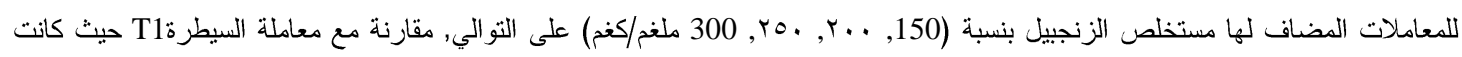

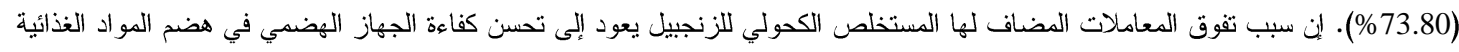

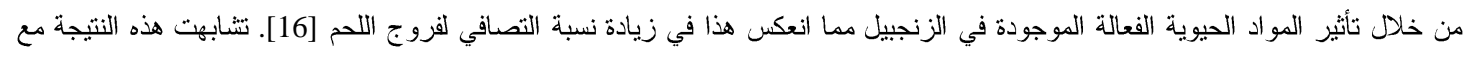

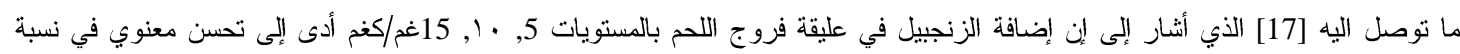
التصافي مقارنة مع معاملة السيطرة. 


\section{CONFLICT OF INTERESTS}

There are no conflicts of interest.

\section{4- References}

[1] United States Department of Agriculture USDA. Proceeding of the American Society of Animal Sci. Washington, DC. 2000

[2] D. H. Al-Hassani, and M. M. Al-Jabri. Effect of smoking by Peganum harmala seeds on sexual performance of white leghorn cocks. 2 (2), 115-122. 2007.

[3] U. Bahandari, R. Kanojia and K. Pillai. Effect of ethanolic extract of Zingiber officinale on dyslipidaemia in diabetes rats J. Ethenopharmacol. 97, 227-230. 2005.

[4] K. Platel and K. Srinivasan. Influence of dietary spices and their active principles on pancreatic digestive enzymes in albino rats. Nahrung. 44, 42-46. 2000.

[5] S. P. Akhani, S. L. Vishwakarma and R. K. Goyal. Anti-diabetic activity of Zingiber officinale in Streptozotocin-induced type I diabetic rats. J. Pharmacy Pharmacol. 56, 101-105. 2004.

[6] S. K. Shalmany and M. Shivazad. The effect of diet propolis supplementation on ross broiler chicks performance. International Journal of Poul. Sci., 5(1), 84-88. 2006.

[7] D. B. Duncan. Multiple range and multiple F-tests. Biometrics. 11, 1-42. 1955.

[8] SAS. SAS User's Guide: Statistics Version. 7.0, SAS Institute, Inc. Cary, NC. USA. 2004.

[9] National Research Council NRC. Nutrient requirements of poultry National academy of science, Washington, DC. 1994.

[10] M. H. Ahmida and M. H. Abuzogaya. The effects of oral administration of green tea and ginger extracts on serum and hepatic lipid content in rats fed a hyperlipidemic diet. J. Appl. Sci. Res., 5, 1709-1713. 2009.

[11] M. H. AL-Rubaie. Effect of some plant extracts in some histological and physiological characteristics of a bird quail. Msc, thesis, Al musiab Technical College. AL-Furat AL-Awsat Technical University. 2013.

[12] M. A. Shalaby and A. R. Hamowieh. Effect of Zingiber officinale Roots and Cinnamon zeylanicum Bark on Fertility of Male Diabetic Rats. Global Veterinaria., 5(6), 341-347. 2010.

[13] U. Jana, R. N. Chattopadhyay, and B. P. Shaw. Preliminary studies on anti-inflammatory activity of Zingber officinale Rosc., Vitex negundo Linn and Tinospora cordifolia (Willid) Miers in albino rats. Indian Jour. Pharmacol., 31, 232-233. 1999.

[14] M. Park, J. Bae and D.S. Lee. Antibacterial activity of 10-gingerol and 12-gingerol isolated from ginger rhizome against periodontal bacteria. Phytother Res. 22 (11), 1446-1449. 2008.

[15] G. F. Zhang, Z. B. Yang, Y. Wang, W. R. Yang, S. Z., Jiang, and G. S. Gai. Effects of ginger root (Zingiber officinale) processed to different particle sizes on growth performance, antioxidant status, and serum metabolites of broiler chickens. Poultry Science. 88, 2159-2166. 2009.

[16] A. Tekeli, H. R. Kutlu, L. Celik and F. Doran 2010. Determination of the Effect of Z. officinale and propolis Extracts on intestinal microbiology and histological characteristics in broiler. 9 (9), 898-906. 2010.

[17] G. O. Farinu, S. G. Ademola, A. O. Ajayi Obe and G. M. Babatunde. Growth, haematological and biochemical studies on garlic and ginger-fed broiler chickens. Moor J. Agric. Res. 5, 122-128. 2004. 